\title{
Single-agent management of diabetes and ischemia reperfusion injury
}

\author{
Richard D. Williams, BS, and Chadrick E. Denlinger, MD
}

\author{
From the Division of Cardiothoracic Surgery, Medical University of South Carolina, Charleston, SC. \\ Disclosures: Authors have nothing to disclose with regard to commercial support. \\ Received for publication Nov 19, 2016; accepted for publication Nov 23, 2016; available ahead of print Jan 5, \\ 2017. \\ Address for reprints: Chadrick E. Denlinger, MD, 114 Doughty St, Suite 201, Charleston, SC 29425 (E-mail: \\ denlinge@musc.edu). \\ J Thorac Cardiovasc Surg 2017;153:711-2 \\ $0022-5223 / \$ 36.00$ \\ Copyright (C 2016 by The American Association for Thoracic Surgery \\ http://dx.doi.org/10.1016/j.jtcvs.2016.11.044
}

Ischemia-reperfusion injury (IRI) leading to primary graft dysfunction remains one of the most feared complications of lung transplantation, and extensive research has explored avenues to mitigate this effect. Primary graft dysfunction severity is measured by the degree of hypoxemia, which is its greatest physiologic consequence. Numerous surrogate markers for IRI and primary graft dysfunction correlating with hypoxemia have been described in research models, including pulmonary edema, recruitment of specific inflammatory cells, and cytokine expression. The inflammatory response in the lungs can become systemic, leading to multiorgan failure.

Previous studies have investigated the utility of pharmacologic inhibition of dipeptidyl peptidase 4 (DPP4), also known as cluster-determining factor 26 (CD26), to minimize IRI. This peptidase cleaves the stromal-derived factor 1 , which recruits bone marrow-derived regenerative cells. Pharmacologic inhibition of CD26/DPP4 preserves stromal-derived factor 1 , theoretically enhancing the recruitment of regenerative cells and minimizing IRI. Pharmacologic inhibition of CD26/DPP4 during lung transplantation in mouse models was first described in 2009, at which time CD26 inhibition was shown to minimize histologic changes and preserve oxygenation for 7 day. $^{1}$ In their article in this issue of the Journal, Jang and colleagues ${ }^{2}$ have expanded on these previous results by extending observations to 14 days, and they have found similar protective effects with CD26/DPP4 inhibition. Beneficial effects of CD26/DPP4 inhibition with vildagliptin have also been demonstrated after cardiac IRI induced by the temporary ligation of the left anterior descending coronary artery in a nontransplant murine model. ${ }^{3}$ Vildagliptin has also been shown to reduce neuronal IRI in rats that were studied for 4 weeks after bilateral carotid artery occlusion. ${ }^{4}$ Collectively, these results suggest that CD26/DPP4 inhibition exerts protective effects against IRI in multiple organ systems.

Vildagliptin is a small molecule inhibitor of DPP4 that is already clinically available for the treatment of diabetes. In

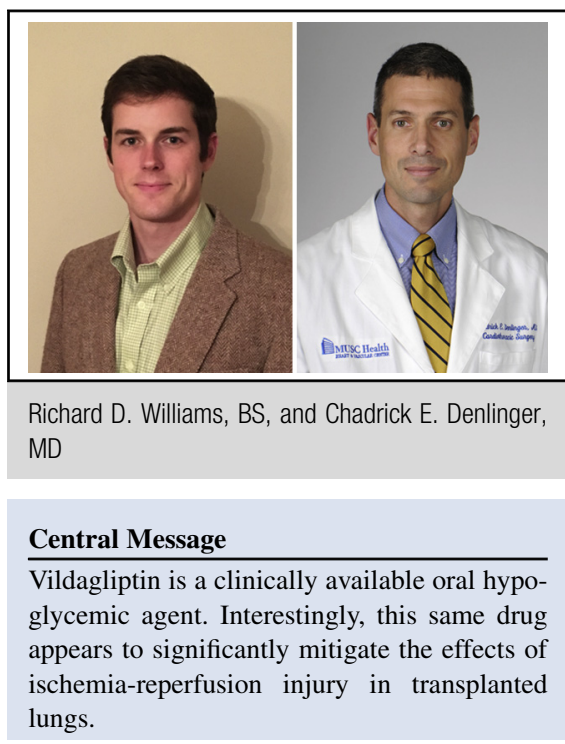

See Article page 713

the pancreas, vildagliptin potentiates the activity of glucagon-like peptide 1 and gastric inhibitory polypeptide by preventing their degradation by DPP4, resulting in increased insulin secretion and reduced glucagon release. The current availability of vildagliptin for the treatment of diabetes and reports of the regenerative potential of DPP4 inhibitors when used in conjunction with colonystimulating factors paves the way for its use in IRI prevention, but it also increases the potential that the observed IRI mitigation may have been related to "off-target effects" rather than to the hypothesized mechanism of CD26/ DPP4 inhibition, preservation of stromal-derived factor 1, and recruitment of progenitor cells. ${ }^{5}$ Regardless, the mechanistic pathway is of academic interest, whereas the physiologic result may have immediate clinical benefits.

Data presented by Jang and colleagues ${ }^{2}$ demonstrate a dramatic reduction of IRI at the histologic level. Unfortunately, the experimental model does not allow an accurate physiologic assessment, because Jang and colleagues ${ }^{2}$ performed single-lung transplants and assessed lung function by measuring systemic arterial blood gas values. As they themselves note, simply comparing mixed systemic blood gases of transplanted mice to those of naive mice is inadequate. If the model had allowed selective pulmonary vein blood gas assessments, the physiologic benefits observed would likely have been more impressive than what was observed histologically. 


\section{References}

1. Zhai W, Jungraithmayr W, De Meester I, Inci I, Augustyns K, Arni S, et al. Primary graft dysfunction in lung transplantation: the role of CD26/ dipeptidylpeptidase IV and vasoactive intestinal peptide. Transplantation. 2009; 87:1140-6.

2. Jang JH, Yamada Y, Janker F, De Meester I, Baerts L, Vliegen G, et al. Antiinflammatory effects on ischemia/reperfusion-injured lung transplants by the cluster of differentiation 26/dipeptidylpeptidase 4 (CD26/DPP4) inhibitor vildagliptin. J Thorac Cardiovasc Surg. 2017;153:713-24.
3. Pongkan W, Pintana H, Jaiwongkam T, Kredphoo S, Sivasinprasasn S, Chattipakorn SC, et al. Vildagliptin reduces cardiac ischemic-reperfusion injury in obese orchiectomized rats. J Endocrinol. 2016;231:81-95.

4. Purnachander K, Rao DS, Kannappan N. Anti neuroinflammatory effect of vildagliptin in ischaemia-reperfusion induced cerebral infraction in normal and STZ induced type-II diabetic rats. Int J Pharmacol Res. 2016;6:97-103.

5. Zaruba MM, Hiergeist L, Mechea A, Kozlik-Feldmann R, Theisen D, Netz H, et al. First treatment of a child suffering from severe ischemic cardiomyopathy with G-CSF and sitagliptin. Int J Cardiol. 2013;170:e41-2. 